\title{
Hospice Care Providers' Knowledge, Attitudes And Practices In China: A Cross-Sectional Study
}

\section{Zhiqun Shu}

Shanghai Ninth People's Hospital, Shanghai Jiaotong University School of Medicine

Limei Jing ( $\square$ Imjing@live.cn )

Shanghai University of Traditional Chinese Medicine

\section{Research Article}

Keywords: Hospice Care, Health Providers, Knowledge, Attitudes, Confidence, Practices, Cross-sectional Study

Posted Date: March 2nd, 2022

DOl: https://doi.org/10.21203/rs.3.rs-927029/v2

License: @ (1) This work is licensed under a Creative Commons Attribution 4.0 International License. Read Full License 


\section{Abstract}

Background: In recently years, China has been growing awareness about the hospice service movement although hospice care was Initially introduced 30 years ago. Hospice care providers' knowledge, attitudes, self-efficiency, and practices status in China should be investigated. This study aims to survey the general actuality of hospice care providers' knowledge, attitudes, and practices of hospice care (KAPHC) in five cities in China, and explore relevant influencing factors.

Method: Relying on our KAPHC scale, we randomly surveyed 3647 valid health care providers in five sampled cities of China in 2019, which respectively represent the north, northeast, east, central, and southwest area. In each city, 14 institutions were selected and 50 health providers were surveyed in each institution. Increment of voluntary participation was accepted. The scaling outcomes were compared among each sampled city-groups with Chi-square test or ANOVA. Multiple correspondence analyses were also performed for further results.

Results: Of all, $41.46 \%$ providers had real experience in providing hospice care, and $58.68 \%$ confirmed willingness of providing. The overall knowledge correct rate was $57.13 \%$. The average scores of threats, benefits, barriers, subjective norms, confidence, and self-report behaviour items were $15.40,41.56,16.75,15.65,41.56$, and 38.61. Providers from eastern China, willing to provide hospice care, or experienced death witness in providing hospice care, proved better score in knowledge, threats, benefits, barriers, subjective norms, confidence, and self-report behaviour $(\mathrm{P}<0.05)$.

Conclusions: The investigation reflected urgent need for systematic training of professional knowledge and skills on hospice care for health care providers. Governments' attention and policy measures are crucial as most Chinese hospice care providers practiced as "organization actors". More attention was need on balanced development of different areas.

\section{Background}

Hospice care improves terminal patients' life quality, and it is the inevitable product of social civilization. It has rapidly expanded through some western developed countries and successfully development since 1967. With national differences in focus and application, it has spread throughout the world ${ }^{[1]}$. However, in mainland China, hospice care has been developing slowly since it was introduced from 30 years ago. In the year of 2015, the Economist Intelligence Unit reports that China's overall rank of 71st out of 80 countries reflects its limited availability and the poor quality of hospice care in general ${ }^{[2]}$.

Till recently years, China has been growing awareness about this movement and it is agreed well with the principle of Health China 2030. Mainly at the municipal level, a series of government polices shifts signaled a trend of greater support and investment in hospice care services. Some first-tier cities like Shanghai have set new targets and policies to increase access to hospice care ${ }^{[3]}$. In 2017, the national health and family planning commission carried out hospice care pilot work in five cities of China, including Beijing, Shanghai, Changchun in Jilin province, Luoyang in Henan, and Deyang in Sichuan province, which distributed in five locations across the country, and focus the hospice care delivery at the grass level. General Practitioners (GPs) and nurses in community health centers (CHCs) or township health centers (THCs) are the core group in this recent movement.

A well-educated hospice care provider can enrich experiences for patients and ease caregiving responsibilities and emotional stress for families. The rising need of hospice care call for more equipped doctors and nurses to provide it. There is evidence that GPs were more likely to feel confident with increasing experience of home care and of caring for cancer patients ${ }^{[4]}$ as well as with a higher number of palliative trajectories for which they had been responsible ${ }^{[5]}$.

Recent investigations highlight the need for timelier and more effective end of life care, however little study revealed the reality of China's status of their knowledge, attitudes, and practices of hospice care providers. Studies conducted in mainland China showed a change on their target population, from nurses ${ }^{[6-8]}$ to specialized doctors ${ }^{[9]}$ and from a single group to multidisciplinary medical team ${ }^{[10,11]}$. However, the majority of those conducted in medical institutions were still on specialist physician and nurses in oncology, intensive care unit, etc. ${ }^{[12-14]}$ Furthermore, till recently in China, there is little literature evidence on exploring the characteristics of localization.

In the current study, we surveyed the general actuality of hospice care providers' knowledge, attitudes and practices of hospice care in five cities, from west to east in China. Furthermore, relevant influencing factors were explored for probably suggestions to practice improvement and relevant policies decision-making. 


\section{Methods \\ Study design and setting}

The study planned to survey 14 institutions in each five cities, and to choose randomly 50 health care providers in each institution. The five sampled cities in China in this study refer to as City A to City E, respectively represent the area of north (City-A), northeast (City-B), east (City-C), central (City-D), and southwest (City-E). And if some institutions were newly approved pilot of hospice care in 2019, they also can be voluntary to take part in the survey. Thus, the total samplings were estimated to be more than 3500 . The anonymous, crosssectional questionnaire survey for particular group was conducted, through the SO JUMP, an online Chinese questionnaire platform. The inclusion criteria were health providers working in health care institution in the cities had voluntarily signed up for the survey in prenotice enrolment. And the exclusion criteria were other care providers in health care institutions or not in voluntary registration book, or those staff who were unable to complete the questionnaire independently. To minimise the probably bias, we conducted a concentrated training in Beijing for all quality controllers from each city and investigate delegates from primary service institutions one week ahead.

\section{Scale}

A structured self-report questionnaire consisting of five parts administered to all subjects. It was health providers' Knowledge, Attitudes, and Practices of Hospice Care (KAPHC) constructed more suitable for Chinese ${ }^{[15]}$. The four parts of the questionnaire included questions on demographic characteristics, knowledge (15items), attitudes (24items with 4 sub-concepts) and practices (22items with 2 subconcepts) on providing hospice care.

The knowledge sheet included questions about concept and philosophy, psychosocial and spiritual care, management of pain and other symptoms, opioid use, policies and localization problems, etc. The four sub-concepts of attitudes were threats ( 5 items), benefits of life quality promotion and death preparation (10 items), barriers ( 5 items) and subjective norms ( 4 items) for providing hospice care. The two sub-concepts of practices were confidence and self-reported practices.

\section{Statistics}

As scaling outcomes, the scores of knowledge, attitude and practices compared by deferent groups in different cities. Statistical analyses were performed using commercial software IBM SPSS Statistics 24.0 (IBM Corporation, Armonk, NY), the threshold of statistical significance set at $P<0.05$ (2-tailed). The Chi-square test or ANOVA were used to compare the characteristics and scores of the 5 citygroups. Multiple correspondence analyses were also performed. The inference in correspondence analyses is whether certain levels of one characteristic (eg, city) are associated with some levels of another characteristic (eg, knowledge).

\section{Results}

From March $18^{\text {th }}$ to $31^{\text {th }}$ in 2019 , total 3647 valid out of 3653 questionnaires were returned (valid rate $99.8 \%$ ). Participants were recruited from 80 grass medical institutes of 5 sampled cities in China. Of all valid questionnaires, 756(20.73\%) were from City-A, 593(16.26\%) were from City-B, 687(18.84\%) from City-C, 580(15.90\%) from City-D and 1031(28.27\%) were from City-E. The average age was $35.65 \pm 9.072$ years old. The social and demographic characteristics of study participants see table 1.

For each item in knowledge scale, the detail choices comparisons of respondents in deferent five cities see table 2. And the multiple comparisons showed that the total scores among 5 cities were statistically different $(F=80.612, P<0.01)$, and ranks in 5 cities were $C>D>E>B>A($ Tamhane, $P<0.05)$.

Table 3 showed attitudes and practices scaling for respondents from different cities. Also with the results of multiple comparisons, the ranks of attitude in five cities were $C>D, E>B, A$ (Tamhane, $P<0.01$ ), of confidence were $C, D>E>A, B$ (Tamhane, $P<0.01$ ), and of self-report practice were $C, E>D>B>A$ (Tamhane, $P<0.05$ ). The mean scores of four attitude sub-concepts were 15.40, 41.56, 16.75 and 15.65, respectively (Table 3). These indicated positive attitudes towards providing hospice care. The most percent respondents agree about the threats of providing hospice care were: "I feel guilty when a patient of mine dies" (51.0\%), "advanced cancer patient is hopeless for cure" (44.3\%). About the barriers toward providing hospice care, $59.0 \%$ responders agree it is a barrier that "Advanced cancer patients have many difficult symptoms". On the other hand, the higher-score items in subjective norms included: "It is meaningful" (4.25), and "It is a part of my duty" (3.94).

The multiple correspondence analyses indicated the most possible influencing factors of Chinese hospice care providers' knowledge, attitude, confidence and self-report practice, details see table 4 .

Page 3/16 
Hospice care providers in City-C, providers who willing to provide hospice care, who have the experience of death witness or experience in providing hospice care, proved better in knowledge, attitude, confidence and self-report behaviour. And those who work in $\mathrm{CHC}$ or THC did worse in knowledge, attitude, confidence and self-report behaviour. Moreover, a) of knowledge, providers with the higher education level, professional title, or as a doctor, would get higher scores and providers in rehabilitation nursing scored lower; $b$ ) of attitude, providers more aged or working in rehabilitation nursing scored lower; c) providers from specialized hospital showed more confidence in practicing; d) of self-report behaviour, doctor and nurse scored higher and men scored higher than women.

The correlation analysis showed high pair wise correlations $(P<0.01)$ between every two measurement dimensions among knowledge, attitude, confidence and self-report practice, details see table 5 .

\section{Discussion}

\section{Overall Situation}

In this investigation, there were $1512(41.46 \%)$ providers had real experience in providing hospice care, and $58.68 \%$ of all confirmed their willingness of providing. It proved those grassroots health service providers' supports in the national hospice movement, from the aspects of their emotional and practical involvement. Furthermore, findings showed that providers who willing to provide hospice care, who have the experience of death witness or experience in providing hospice care, proved better in knowledge, attitude, confidence and self-report practice, which was partly proved by some previous researches $[6,11,16,17]$. We could know from that the exploration and practice of service provider is the key to break through the bottleneck. Primary medical institutions had accumulated certain manpower reserves and practical experience through institutional investment and talent training. As the country attached great importance to it and governments at all levels took active measures, the cause of hospice care in China has developed as if it woke up in winter and waited for the spring to blossom ${ }^{[18]}$. Hospice care in China has a distinct national characteristic of government leadership and policy support ${ }^{[3,19]}$. What about the other side of the coin? This investigation also showed a negative correlation between primary medical institutions and knowledge, attitude, confidence and practice, which probably indicated a relatively poor service quality and most urgent need for systematic training in the main force. Furthermore, systemic barriers to provision of hospice care among GPs need to be identified and addressed. ${ }^{[20,21]}$

Among the five sampled area, hospice care providers in City-C proved better in knowledge, attitude and behavior. This reflects the uneven development of hospice services across the country. Hospice services in the east of China have a long history. As early as October 1988, Shanghai Nanhui Elderly Nursing Hospital was established, taking the lead in carrying out hospice care services ${ }^{[22]}$. And till the year of 2018 , Shanghai was the only city in the nationwide where the local government has issued a statement and special funds to promote hospice care ${ }^{[3,23]}$. It also played a great role in stimulating the development of surrounding eastern cities.

\section{Knowledge}

The overall correct rate of hospice care providers in the investigation was $57.13 \%(8.57 / 15)$, which was close to $60 \%$ as the calibrating in original scale design. We thought the result is patchy at best. Seeing into each item, hospice care providers were lack of cognition in philosophy and principles of hospice care, pain and symptom management, opioid use, and psychosocial and spiritual care.

The first item "the provision of hospice care requires emotional detachment" was quoting from PCQN developed by Ross $\mathrm{M} M$ et al. The difficulty index of this item was $0.67 \sim 0.93$ for sampled nurses in her study ${ }^{y}{ }^{[24]}$. In this study, it was the most difficult item with the difficulty index of 0.15 , and from 0.1 to 0.24 in the different five sampled areas, also as low as the difficulty of 0.19 in the pre-testing ( $u=$ $1.11, P=0.133>0.05$ ). Apart from possible confounders of the scale translated into Chinese, it does reflect the lack of understanding among the respondents. Health service providers often must face the death in routine clinical work, and it is even more common for hospice caregivers in taking care for dying patients. It is undoubtedly a great challenge to meet all needs including emotional needs of the dying patients, thus hospice caregivers need to be prepared well and have a positive attitude. Chinese hospice providers practiced worse on item No.7, No.9 and No.10 in this investigation than those in PCQN as the correct rate were $0.31,0.39$, and 0.28 respectively. The sixth item was about hospice care for special people, with a high difficulty and low correct rate of 0.36 . If hospice care givers never be systemically well trained before, they would be more likely to answer wrong influenced by their traditional ideas and unique bereavement culture in China ${ }^{[25]}$. The eighth item was for Traditional Chinese Medicine (TCM) in hospice care. Its total correct rate was 0.47 , lower than pre-testing, and furthermore in City-A the rate was as low as 0.28 . It showed a weak point of knowledge for hospice caregivers and there was also an uneven among different areas. In the hospice movement in China, as a local characteristic, it is valuable and necessary to actively create conditions to explore and develop some TCM appropriate techniques, especially for the symptom alleviation and the quality of life improvement. However, in modern medicine the speed of TCM development was not so fast to match its broad and 
profound theory system. ${ }^{[26,27]}$ To master the knowledge of TCM, to accelerate the development and implementation of TCM clinical guidelines and to apply appropriate techniques properly are both the need of TCM and hospice developments.

\section{Attitude}

Their mean of totaling score of attitude were 92.22 for all the 24 items. Across the five cities, hospice care providers in City-C scores as high as 96.99 . The four sub-concepts also indicated positive attitudes towards providing hospice care. This study showed that respondents agree about the most threats of providing hospice care were "I feel guilty when a patient of mine dies" (51.0\%), and "advanced cancer patient is hopeless for cure" (44.3\%), which is similar to Liu's study ${ }^{[28]}$. In general, providers in this study have a high agreement with the benefits of hospice care. It showed that the proportion of respondents who agreed with the benefits of improving quality of life is over $80 \%$. Which means that they generally agree with the role of providing hospice care in improving quality of life. More than $80 \%$ of respondents also agreed that hospice care is helpful for patients and families on preparing to death, as "respect for patient's religion and burial rites", "better communication with advanced patients", and "help medical staff to take care of patients better". However, the agreements were relatively lower on "help to die at home" and "avoid the idea of euthanasia" those proportion were around 55\%. It may be related to the lower service rate of hospice care at home than hospice care at institution in China. Most respondents agreed on the social value of hospice care, they thought "it is meaningful" (85.82\%), "it is a part of duty" $(74.39 \%)$, and $62.60 \%$ of them reflected that they chose hospice care because they got "the approval and support of department leader, colleagues, relatives and friends". It can be considered that the choice of hospice care providers in medical institutions in China to engage in hospice care service work was based on the role norm of "organization actor". Their behavioural choice was often from the perspective of the organization. They thought hospice care service as a business behaviour, and their performance was subject to the arrangement of the organization leader. Therefore, the attention and corresponding policy measures of governments are crucial. In addition, more than half of the respondents (58.63\%) experienced the death of family member, which affected them to provide hospice care. It proved that the understanding of life and death, and hospice service delivery could be deepened or changed by witness or observation of the experience of important people around, which embodies the connotation of "neighbourhood effect" [29].

\section{Practices}

The confidence of providing hospice care and their self-report practices on hospice care were to scale a caregivers' behaviour. The mean of totalling scores were 41.56 and 38.61 in their self-evaluated confidence and practice.

The confidence of providing "pain assessment of patients" and "alleviate pain and discomfort of dying patients" was $74.48 \%$ and $68.00 \%$, respectively, while confidence to "guide the management of afterwards and funeral preparation for families" was the lowest (62.21\%). General practitioners and other health care providers in CHCs or THCs considered non-physical abilities (spiritual, cultural, ethical, and legal, etc.) almost as important as pain and symptom control, but most of them lack confidence in their non-physical abilities

[30]. Furthermore, the overall average age of the respondents was 35.65 years old, and their personal experience was relatively inexperienced. If they did not receive systematic training, it would be difficult to improve their confidence of providing such guidance services. The confidence to "coordinate the media resources of medical, social, psychological and spiritual care?" was also relatively low, reflecting that they still need to improve in mobilizing the health care system and social forces to provide coordinated care. The self-report practice is strongly related to knowledge, attitude and confidence $(P<0.001)$. This current study didn't analyse how the confidence and self-report practice influence each other $(r=0.631)$, which need to be further confirmed. Respondents were more confident to coordinate the media resources of medical, social, psychological and spiritual care (3.70) however they did practice so enough (3.42). And they practice less in guiding the body cuisine and funeral preparation for families (3.16) with also a relatively low confident to do (3.62). Currently $41.46 \%$ of all respondents already had experience in providing hospice care, and the general mean score of self-report practice is 3.51(38.61/11) which means the frequency was between "occasionally" and "often". It indicated that for professional full-time hospice care providers, they should increase their practices frequency.

\section{Strengths and Limitation}

This study adopted a scientific and localized developed scale to survey the general actuality of hospice care providers' knowledge, attitudes and practices of hospice care in five cities, from west to east in China. Relevant influencing factors explored through multiplefactor analysis for probably suggestions to improve. The investigation was conducted under the background of the national hospice care pilot work to explore the deep causes of the low death quality in China from the perspective of medical service providers. It provided a baseline for promoting the provision and utilization of hospice care services in China, it could also be evidence on exploring the characteristics of localization at primary health service institutions for improving the quality of hospice care services, and improving the quality of life of patients in their "last mile of life". 
It still has some selection bias, as we conduct a stratified random sampling. In actual operation, we investigated all of staff in those institutions which had total staff less than 50 and, if some CHCs or THCs were newly approved pilot institutions of hospice care in 2019, they also can be voluntary to take part in the survey. Secondly, in this survey, some respondents were not primarily responsible for hospice care work, and may not do it in the future according to for institutional arrangements and personal willingness. In addition, we only sampled 5 cities on behalf of 5 areas of China maybe not so strong evidence. If conditions permit, sampling should be expanded in further study. To scale a hospice care provider's behaviour, we designed the confidence of providing hospice care and self-report practice however it is still not so ideal way to evaluate a person's true behaviour. To explain better the potential meaning of data, a mix method research may be a solution.

\section{Conclusion}

Hospice care, as an integral part of human's life cycle health management, has increasingly become an important livelihood issue of common concern. The development of hospice care in China is still in its infancy, and the long march has just begun. There are still many practical problems to be solved.

The investigation of hospice caregivers' knowledge, attitudes and practices reflected the urgent need for systematic training of professional knowledge and skills in primary medical institutions. And for future formulation of training programs, the study-results of both suppliers and buyers should both be considered. The quality and quantity of hospice service should be both attached importance to and promoting it. In addition, we should pay more attention to the equity issues on balanced development of different areas, draw on the valuable experience of the eastern area in the development of hospice care, and put the work into practice.

\section{List Of Abbreviations}

\begin{tabular}{|ll|}
\hline knowledge, attitudes, and practices of hospice care & KAPHC \\
\hline General Practitioner & GP \\
\hline community health center & CHC \\
\hline township health center & THC \\
\hline Traditional Chinese Medicine & TCM \\
\hline
\end{tabular}

\section{Declarations}

\section{Ethics approval and consent to participate}

The design of the study and participants' selection performed in accordance with the Declaration of Helsinki and were approved by the ethical review committee of Ninth People's Hospital Affiliated to Medical School of Shanghai Jiaotong University (No.SH9H-2021-T11-1). It did not involving any human material, or human data. The respondents were told in advance about the anonymous investigation and informed consent was obtained.

\section{Consent for publication}

Not applicable.

\section{Availability of data and materials}

All data generated or analysed during this study are included in this published article.

\section{Competing interests}

The authors declare that they have no competing interests.

\section{Funding}

The fund of Ministry of Education of China(20YJAZH045) supported data collection, the funds of Shanghai Plan of Philosophy and Social Science (2019BGL032) and Shanghai Pujiang Program (2019PJC099) supported article writing. Corresponding author Dr. Limei 
Jing is the lead and takes responsibility for above-mentioned funds.

\section{Authors' contributions}

ZS made substantial contributions to data collection, analysis and interpretation and drafted the manuscript. LJ made contributions to research design and survey, and also contributed to draw a conclusion for the revised manuscript. All authors reviewed and approved the final manuscript.

\section{Acknowledgements}

We are grateful to all involved in the study. We sincerely thank the support of colleagues from research department of Chinese Association for Life Care for their supportive work that helped in surveying stage. And also grateful to all organizations that funded this research.

\section{References}

1. Bernat, James L. Ethical Issues in Neurology. 3rd ed. Lippincott Williams \& Wilkins. 2008. p. 154.

2. The Economist Intelligence Unit (EIU). 2015 Quality of Death Index. http://www.virtualhospice.ca/Assets/2015\%20Quality\%20of\%20Death\%20Index_20151013163458.pdf (2015). Accessed 13 Oct 2015.

3. Limei J, Hongwei L, Kun L, et al. Evaluation of the Palliative Care Input and Output Effect of Community Health Service Centers in Shanghai. Chinese General Practice, 2016, 19(34):4178-4182. DOI:10.3969/j.issn.1007-9572.2016.34.006.

4. Guomei G, Sufen H, Wei Z, et al. Attitude of hospice care and influencing factors among medical staff in Quanzhou area. Journal of Nursing Science, 2017, 32(13):49-52. DOI: 10.3870/j.issn.1001-4152.2017.13.049.

5. Jing Y, Yufang Q, Yunzhen X, et al. Investigation and analysis on the attitude of oncology nurses to hospice care in 6 hospitals in Shanxi Province. Chinese Remedies \& Clinics, 2018,18(S1):23-25. DOI: 10.11655/zgywylc2018.Suppl.009.

6. Lei X. Investigation on nurses' cognition about terminal care. Chinese Journal of Nursing Education, 2007, 4(1):31-33. DOI: 10.3761/j.issn.1672-9234.2007.01.013 (In Chinese)

7. Chunli G, Changxiang C. Investigation and analysis of nurses' attitudes towards hospice care. Journal of Qiqihar College, 2007, 28(4):506-507. DOI: 10.3969/j.issn.1002-1256.2007.04.074.

8. Yaying K, Jianping W, Zhili Z, et al. Survey and analysis of nurses' hospice care attitude and cognition level in the third grade A hospitals in Nanning city. Chinese Nursing Research, 2015(34):4316-4318. DOI: 10.3969/j.issn.1009-6493.2015.34.033.

9. Gu X, Cheng W. Chinese oncologists' knowledge, attitudes and practice towards palliative care and end of life issues. BMC Medical Education, 2016, 16(1):149. DOI: 10.1186/s12909-016-0668-3.

10. Yueping Z. Study on hospice care knowledge, attitude of physicians and nurses and relation. MD Thesis, Central South University, China, 2008.

11. Guomei G, Sufen H, Wei Z, et al. Attitude of hospice care and influencing factors among medical staff in Quanzhou area. Journal of Nursing Science, 2017, 32(13):49-52. DOI: 10.3870/j.issn.1001-4152.2017.13.049.

12. Jing Y, Yufang Q, Yunzhen X, et al. Investigation and analysis on the attitude of oncology nurses to hospice care in 6 hospitals in Shanxi Province. Chinese Remedies \& Clinics, 2018,18(S1):23-25. DOI: 10.11655/zgywylc2018.Suppl.009.

13. Min W, Hongju Y, Lu F, et al. A survey on the cognition and behavior of hospice care of tumor medical staff in general hospital in Shandong province. Journal of Qilu Nursing, 2017(13):35-38. DOI: 10.3969/j.issn.1006-7256.2017.13.011.

14. Ruiyu H, Mingtao Q, Yongchun Z, et al. A survey on the knowledge, attitude and practice of hospice care among medical staff. Guangdong Medical Journal, 2017, 38(12):1905-1908.DOI: 10.3969/j.issn.1001-9448.2017.12.032.

15. Shu Z, Wang Y, Li T, Jing L, Sun X. Instrument development of health providers' Knowledge, Attitude and Practice of Hospice Care Scale in China. Int J Health Plann Manage. Epub ahead of print 15 Oct 2020. DOI: 10.1002/hpm.3074.

16. Liping W. Revise and application of Chinese Version of Frommelt Attitudes Toward Care of the Dying Scale Form B. PhD Thesis, Southern Medical University, China, 2016.

17. Bergman J, Lorenz K A, Ballon-Landa E, et al. A Scalable Web-Based Module for Improving Surgical and Medical Practitioner Knowledge and Attitudes about Palliative and End-of-Life Care. Journal of Palliative Medicine, 2015, 18(5):415-420. DOI: 10.1089/jpm.2014.0349. Epub 2015 Mar 6. 
18. Shuzhen D, Jing Z, Xueru Z, et al. History, development and prospect of hospice care. Medical Research and Education, 2011.08,35(1) : 7-12. DOI:10.3969/j.issn.1674-490X.2018.01.002.

19. Yao C, Junyan W, Yongxing S. Functions of Hospice Care Service and Its Resource in Chendu, Kunming and Hangzhou. Chinese General Practice, 2011(01):76-79. DOI:10.3969/j.issn.1007-9572.2011.01.022.

20. Groot MM, Vernooij-Dassen MJ, Crul BJ, Grol RP. General practitioners (GPs) and palliative care: perceived tasks and barriers in daily practice. Palliat Med. 2005; 19(2):111-8. DOI: 10.1191/0269216305pm937oa.

21. Slort W, Schweitzer BP, Blankenstein AH, Abarshi EA, Riphagen II, Echteld MA, Aaronson NK, van der Horst H, Deliens L. Perceived barriers and facilitators for general practitioner-patient communication in palliative care: a systematic review. Palliat Med. 2011; 25(6):613-29. DOI: 10.1177/0269216310395987. Epub 2011 Jan 27.

22. Yongxing S, Guangrong W, Research on the status quo and Policies of Urban Hospice care services in China. Shanghai: Shanghai Science and Technology Education Press, 2010, p.2.

23. Limei J, Wenyu C, Zhiqun S, Shuijing L, Yongxing S. The Evaluation of Hospice Care Service Quality in pilot institutions in Shanghai. Annual Report on Health Policy Research in Shanghai, China, 2018.

24. Ross MM, McDonald B, McGuinness J. The palliative care quiz for nursing (PCQN): the development of an instrument to measure nurses' knowledge of palliative care. J Adv Nurs. 1996; 23(1):126-37. DOI: 10.1111/j.1365-2648.1996.tb03106.x.

25. Xiaoshan T. When Palliative Medicine is Culturalized, PhD Thesis, Central South University, China, 2009.

26. Shuiying Y. Reasons for slow development of traditional Chinese medicine and its prospect. Modern Journal of Integrated Traditional Chinese and Western Medicine, 2007; 16(13): 32-33. DOI:10.3969/j.issn.1008-8849.2007.13.016.

27. Yicao Z, Lixin G. Popularization of science and technology is the only way to solve the tardiness development of TCM. Clinical Journal of Chinese Medicine, 2011; 03(5):118-120. DOI:10.3969/j.issn.1674-7860.2011.05.067.

28. Buck N. Identifying Neighbourhood Effects on Social Exclusion. Urban Studies. 2001; 38(12):2251-2275. DOI:10.1080/00420980120087153

29. Liu W, Hu W, Chiu Y, et al. Factors that influence physicians in providing palliative care in rural communities in Taiwan. Support Care Cancer. 2005; 13(10). DOI: 10.1007/s00520-005-0778-7.

30. Giezendanner S, Jung C, Banderet HR, et al. General Practitioners' Attitudes towards Essential Competencies in End-of-Life Care: A Cross-Sectional Survey. PLoS One. 2017; 12(2):e0170168. DOI: 10.1371/journal.pone.0170168.

\section{Tables}

Table 1. The Social and Demographic Characteristics of Study Participants 


\begin{tabular}{|c|c|c|c|c|c|c|c|c|}
\hline City & & A & B & C & D & $E$ & Total & $x^{2}$ \\
\hline \multirow[t]{2}{*}{ Gender } & male & $130(17.20)$ & $89(15.01)$ & $115(16.74)$ & 153(26.38) & 228(22.11) & 715(19.61) & $35.32 * \star$ \\
\hline & female & $626(82.80)$ & 504(84.99) & $572(83.26)$ & $427(73.62)$ & 803(77.89) & 2932(80.39) & \\
\hline \multirow[t]{4}{*}{ Age } & $29-$ & $169(22.35)$ & 128(21.59) & 129(18.78) & $200(34.48)$ & 394(38.22) & $1020(27.97)$ & $162.23^{\star \star}$ \\
\hline & $30-39$ & $314(41.53)$ & $245(41.32)$ & $306(44.54)$ & $232(40.00)$ & $433(42.00)$ & $1530(41.95)$ & \\
\hline & $40-49$ & $191(25.26)$ & $149(25.13)$ & 188(27.37) & 111(19.14) & 155(15.03) & 794(21.77) & \\
\hline & $50+$ & $82(10.85)$ & $71(11.97)$ & $64(9.32)$ & $37(6.38)$ & $49(4.75)$ & $303(8.31)$ & \\
\hline \multirow[t]{2}{*}{ Nationality } & han & $721(95.37)$ & $557(93.93)$ & $674(98.11)$ & $567(97.76)$ & $1025(99.42)$ & $3544(97.18)$ & $53.53^{\star \star}$ \\
\hline & non-han & $35(4.63)$ & $36(6.07)$ & 13(1.89) & $13(2.24)$ & $6(0.58)$ & $103(2.82)$ & \\
\hline \multirow{2}{*}{$\begin{array}{l}\text { Religious } \\
\text { Belief }\end{array}$} & yes & $37(4.89)$ & $44(7.42)$ & 73(10.63) & $58(10.00)$ & $120(11.64)$ & $332(9.10)$ & $28.72^{\star \star}$ \\
\hline & no & $719(95.11)$ & $549(92.58)$ & 614(89.37) & $522(90.00)$ & $911(88.36)$ & $3315(90.90)$ & \\
\hline \multirow{3}{*}{$\begin{array}{l}\text { Marriage } \\
\text { status }\end{array}$} & unmarried & 121(16.01) & 119(20.07) & 131(19.07) & $127(21.90)$ & 239(23.18) & $737(20.21)$ & $21.78 \star \star$ \\
\hline & married & $620(82.01)$ & 458(77.23) & $536(78.02)$ & $444(76.55)$ & $759(73.62)$ & $2817(77.24)$ & \\
\hline & $\begin{array}{l}\text { divorced or } \\
\text { widowed }\end{array}$ & 15(1.98) & $16(2.70)$ & $20(2.91)$ & $9(1.55)$ & $33(3.20)$ & $93(2.55)$ & \\
\hline \multirow[t]{3}{*}{$\begin{array}{l}\text { Education } \\
\text { status }\end{array}$} & $\begin{array}{l}\text { bachelor or } \\
\text { above }\end{array}$ & $487(64.42)$ & $306(51.60)$ & $502(73.07)$ & $330(56.90)$ & $457(44.33)$ & 2082(57.09) & $175.24 * \star$ \\
\hline & college & $225(29.76)$ & $220(37.10)$ & $159(23.14)$ & $214(36.90)$ & $479(46.46)$ & $1297(35.56)$ & \\
\hline & $\begin{array}{l}\text { high school } \\
\text { or less }\end{array}$ & $44(5.82)$ & $67(11.30)$ & $26(3.78)$ & $36(6.21)$ & $95(9.21)$ & 268(7.35) & \\
\hline \multirow[t]{4}{*}{ Job } & administrator & $74(9.79)$ & 48(8.09) & $65(9.46)$ & $116(20.00)$ & 107(10.38) & $410(11.24)$ & $126.14^{\star \star}$ \\
\hline & doctor & $289(38.23)$ & $230(38.79)$ & $276(40.17)$ & $170(29.31)$ & $315(30.55)$ & $1280(35.10)$ & \\
\hline & nurse & $310(41.01)$ & $262(44.18)$ & $278(40.47)$ & 180(31.03) & $452(43.84)$ & $1482(40.64)$ & \\
\hline & $\begin{array}{l}\text { medical } \\
\text { technician }\end{array}$ & $83(10.98)$ & $53(8.94)$ & $68(9.90)$ & 114(19.66) & $157(15.23)$ & $475(13.02)$ & \\
\hline \multirow{4}{*}{$\begin{array}{l}\text { Profession } \\
\text { title }\end{array}$} & senior & $91(12.04)$ & $73(12.31)$ & $53(7.71)$ & $38(6.55)$ & $71(6.89)$ & $326(8.94)$ & $198.87 * \star$ \\
\hline & intermediate & 296(39.15) & $136(22.93)$ & $328(47.74)$ & $189(32.59)$ & $237(22.99)$ & $1186(32.52)$ & \\
\hline & junior & $311(41.14)$ & $314(52.95)$ & $267(38.86)$ & $285(49.14)$ & 595(57.71) & 1772(48.59) & \\
\hline & none & $58(7.67)$ & $70(11.80)$ & $39(5.68)$ & $68(11.72)$ & $128(12.42)$ & $363(9.95)$ & \\
\hline \multirow[t]{4}{*}{$\begin{array}{l}\text { Organization } \\
\text { type }\end{array}$} & $\begin{array}{l}\text { secondary or } \\
\text { above }\end{array}$ & $111(14.68)$ & 178(30.02) & $112(16.30)$ & $341(58.79)$ & $592(57.42)$ & $1334(36.58)$ & $1062.16^{\star \star \star}$ \\
\hline & $\mathrm{CHC}$ or THC & $522(69.05)$ & 415(69.98) & $510(74.24)$ & $179(30.86)$ & 288(27.93) & $1914(52.48)$ & \\
\hline & $\begin{array}{l}\text { specialized } \\
\text { hospital }\end{array}$ & $0(0.00)$ & $0(0.00)$ & $53(7.71)$ & $25(4.31)$ & $119(11.54)$ & $197(5.40)$ & \\
\hline & $\begin{array}{l}\text { rehabilitation } \\
\text { nursing }\end{array}$ & $123(16.27)$ & $0(0.00)$ & $12(1.75)$ & $35(6.03)$ & $32(3.10)$ & $202(5.54)$ & \\
\hline \multirow{2}{*}{$\begin{array}{l}\text { Commonweal } \\
\text { character }\end{array}$} & public & 633(83.73) & $579(97.64)$ & $675(98.25)$ & 492(84.83) & $932(90.40)$ & $3311(90.79)$ & $148.90 * *$ \\
\hline & non-public & $123(16.27)$ & $14(2.36)$ & $12(1.75)$ & $88(15.17)$ & $99(9.60)$ & $336(9.21)$ & \\
\hline \multirow{2}{*}{$\begin{array}{l}\text { Experience of } \\
\text { death witness }\end{array}$} & yes & $536(70.90)$ & $367(61.89)$ & $590(85.88)$ & $392(67.59)$ & $788(76.43)$ & $2673(73.29)$ & $112.06 * \star$ \\
\hline & no & $220(29.10)$ & $226(38.11)$ & $97(14.12)$ & $188(32.41)$ & $243(23.57)$ & $974(26.71)$ & \\
\hline \multirow{2}{*}{$\begin{array}{l}\text { Experience in } \\
\text { providing } \\
\text { hospice care }\end{array}$} & yes & $150(19.84)$ & $160(26.98)$ & $437(63.61)$ & $305(52.59)$ & $460(44.62)$ & $1512(41.46)$ & $369.49 * *$ \\
\hline & no & $606(80.16)$ & $433(73.02)$ & $\begin{array}{c}250(36.39) \\
\text { Page } 9 / 16\end{array}$ & $275(47.41)$ & $571(55.38)$ & $2135(58.54)$ & \\
\hline
\end{tabular}




\begin{tabular}{|c|c|c|c|c|c|c|c|}
\hline \multirow{2}{*}{$\begin{array}{l}\text { Willingness } \\
\text { of providing }\end{array}$} & yes & $338(44.71)$ & $287(48.40)$ & $471(68.56)$ & 421(72.59) & $623(60.43)$ & $2140(58.68)$ \\
\hline & no & 418(55.29) & $306(51.60)$ & 216(31.44) & $159(27.41)$ & 408(39.57) & $1507(41.32)$ \\
\hline Total & & $756(100.0)$ & 593(100.0) & $687(100.0)$ & $580(100.0)$ & 1031(100.0) & $3647(100.0)$ \\
\hline
\end{tabular}

$\mathrm{CHC}$, community health center; THC, township health center.

Table 2. The Knowledge Scaling of Each Item for Respondents from Different Cities 


\section{Knowledge items}

1. The provision of hospice care requires emotional detachment.
2. Psychological, social, and spiritual problems are paramount to the hospice care team who give appropriate consultation and management.

\begin{tabular}{llllllll} 
City & N & Mean & SD & SE & $95 \%$ Cl & F & Sig. \\
\cline { 1 - 5 } A & 756 & 0.1 & 0.3 & 0.01 & $0.08 \sim 0.12$ & \multirow{2}{*}{16.43} & $\otimes 0.01^{\star *}$ \\
B & 593 & 0.14 & 0.34 & 0.01 & $0.11 \sim 0.16$ & & \\
C & 687 & 0.24 & 0.43 & 0.02 & $0.21 \sim 0.28$ & & \\
D & 580 & 0.16 & 0.36 & 0.02 & $0.13 \sim 0.18$ & & \\
\cline { 1 - 5 } E & 1031 & 0.13 & 0.34 & 0.01 & $0.11 \sim 0.15$ & & \\
\cline { 1 - 5 } Total & 3647 & 0.15 & 0.36 & 0.01 & $0.14 \sim 0.16$ & &
\end{tabular}

\begin{tabular}{llllllll} 
A & 756 & 0.86 & 0.35 & 0.01 & $0.83 \sim 0.88$ & 7.37 & $\otimes 0.01$ ** \\
\cline { 1 - 5 } B & 593 & 0.89 & 0.32 & 0.01 & $0.86 \sim 0.91$ & &
\end{tabular}

$\begin{array}{llllll}\text { C } & 687 & 0.89 & 0.31 & 0.01 & 0.87 \sim 0.92\end{array}$

$\begin{array}{llllll}D & 580 & 0.94 & 0.24 & 0.01 & 0.92 \sim 0.96\end{array}$

E $\quad 1031 \quad 0.91 \quad 0.28 \quad 0.01 \quad 0.90 \sim 0.93$

$\begin{array}{llllll}\text { Total } & 3647 & 0.9 & 0.3 & 0.01 & 0.89 \sim 0.91\end{array}$

3. Three steps make up the WHO analgesic ladder.

\begin{tabular}{|c|c|c|c|c|c|c|}
\hline A & 756 & 0.78 & 0.41 & 0.01 & $0.75 \sim 0.81$ & $\nabla 0.01^{\star *}$ \\
\hline B & 593 & 0.82 & 0.38 & 0.02 & $0.79 \sim 0.85$ & \\
\hline
\end{tabular}

4. The hospice care team provides bereavement support for the family after the patient's death.
5. Home Hospice care is in line with China's folk customs.
6. For child bereavement care, children can attend funerals and even participate in preparations.
7. During the terminal stages of an illness, drugs that can cause respiratory depression are appropriate for

\begin{tabular}{llllll} 
C & 687 & 0.91 & 0.28 & 0.01 & $0.89 \sim 0.94$ \\
\hline D & 580 & 0.87 & 0.34 & 0.01 & $0.84 \sim 0.89$
\end{tabular}

E $\quad \begin{array}{lllll}1031 & 0.86 & 0.35 & 0.01 & 0.84 \sim 0.88\end{array}$

Total $3647 \quad 0.85 \quad 0.36 \quad 0.01 \quad 0.84 \sim 0.86$

$\begin{array}{llllllll}A & 756 & 0.65 & 0.48 & 0.02 & 0.62 \sim 0.69 & 31.19 & \otimes 0.01 \text { ** }\end{array}$

$\begin{array}{llllll}\text { B } & 593 & 0.61 & 0.49 & 0.02 & 0.57 \sim 0.65\end{array}$

$\begin{array}{llllll}\text { C } & 687 & 0.84 & 0.37 & 0.01 & 0.81 \sim 0.86\end{array}$

$\begin{array}{llllll}\text { D } & 580 & 0.8 & 0.4 & 0.02 & 0.77 \sim 0.83\end{array}$

$\begin{array}{llllll}\text { E } & 1031 & 0.68 & 0.47 & 0.01 & 0.65 \sim 0.71\end{array}$

Total $3647 \quad 0.71 \quad 0.45 \quad 0.01 \quad 0.70 \sim 0.73$

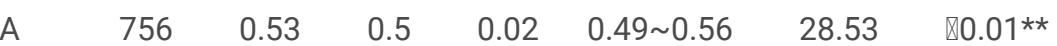

$\begin{array}{llllll}\text { B } & 593 & 0.61 & 0.49 & 0.02 & 0.57 \sim 0.65\end{array}$

$\begin{array}{llllll}\text { C } & 687 & 0.79 & 0.41 & 0.02 & 0.76 \sim 0.82\end{array}$

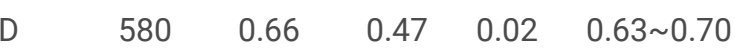

E $\quad \begin{array}{lllll}1031 & 0.65 & 0.48 & 0.01 & 0.62 \sim 0.68\end{array}$

Total $\quad 3647 \quad 0.64 \quad 0.48 \quad 0.01 \quad 0.63 \sim 0.66$

$\begin{array}{llllllll}\text { A } & 756 & 0.3 & 0.46 & 0.02 & 0.26 \sim 0.33 & 21.08 & \nabla 0.01 \text { ** }\end{array}$

$\begin{array}{llllll}\text { B } & 593 & 0.29 & 0.45 & 0.02 & 0.26 \sim 0.33\end{array}$

$\begin{array}{llllll}\text { C } & 687 & 0.5 & 0.5 & 0.02 & 0.46 \sim 0.54\end{array}$

$\begin{array}{llllll}D & 580 & 0.34 & 0.47 & 0.02 & 0.30 \sim 0.38\end{array}$

$\begin{array}{llllll}\text { E } & 1031 & 0.36 & 0.48 & 0.01 & 0.33 \sim 0.39\end{array}$

Total $3647 \quad 0.36 \quad 0.48 \quad 0.01 \quad 0.34 \sim 0.37$

$\begin{array}{llllllll}\text { A } & 756 & 0.27 & 0.45 & 0.02 & 0.24 \sim 0.31 & 2.79 & 0.025^{*}\end{array}$

Page $11 / 16$ 
$\begin{array}{llllll}\text { B } & 593 & 0.33 & 0.47 & 0.02 & 0.29 \sim 0.37\end{array}$

$\begin{array}{llllll}\text { C } & 687 & 0.28 & 0.45 & 0.02 & 0.25 \sim 0.31\end{array}$

$\begin{array}{llllll}\text { D } & 580 & 0.33 & 0.47 & 0.02 & 0.29 \sim 0.36\end{array}$

$\begin{array}{llllll}\text { E } & 1031 & 0.33 & 0.47 & 0.01 & 0.30 \sim 0.36\end{array}$

$\begin{array}{llllll}\text { Total } & 3647 & 0.31 & 0.46 & 0.01 & 0.29 \sim 0.32\end{array}$

8. To use Mirabilite in Shenque acupoint application can relieve ascites.

$\begin{array}{llllllll}\text { A } & 756 & 0.28 & 0.45 & 0.02 & 0.24 \sim 0.31 & 70.17 & \otimes 0.01^{* *}\end{array}$

9. Pain threshold is lowered by fatigue or anxiety.

$\begin{array}{llllll}\text { B } & 593 & 0.4 & 0.49 & 0.02 & 0.36 \sim 0.44\end{array}$

$\begin{array}{llllll}\text { C } & 687 & 0.68 & 0.47 & 0.02 & 0.65 \sim 0.72\end{array}$

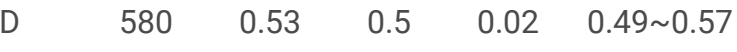

E $\quad \begin{array}{lllll}1031 & 0.48 & 0.5 & 0.02 & 0.45 \sim 0.51\end{array}$

$\begin{array}{llllll}\text { Total } & 3647 & 0.47 & 0.5 & 0.01 & 0.46 \sim 0.49\end{array}$

$\begin{array}{llllllll}\text { A } & 756 & 0.38 & 0.49 & 0.02 & 0.35 \sim 0.42 & 4.98 & 0.001^{\text {** }}\end{array}$

$\begin{array}{llllll}\text { B } & 593 & 0.38 & 0.49 & 0.02 & 0.34 \sim 0.42\end{array}$

$\begin{array}{llllll}\text { C } & 687 & 0.45 & 0.5 & 0.02 & 0.41 \sim 0.48\end{array}$

$\begin{array}{llllll}\text { D } & 580 & 0.41 & 0.49 & 0.02 & 0.37 \sim 0.45\end{array}$

$\begin{array}{llllll}\text { E } & 1031 & 0.34 & 0.48 & 0.01 & 0.31 \sim 0.37\end{array}$

$\begin{array}{llllll}\text { Total } & 3647 & 0.39 & 0.49 & 0.01 & 0.37 \sim 0.40\end{array}$

10. Men generally reconcile their grief more quickly than women.

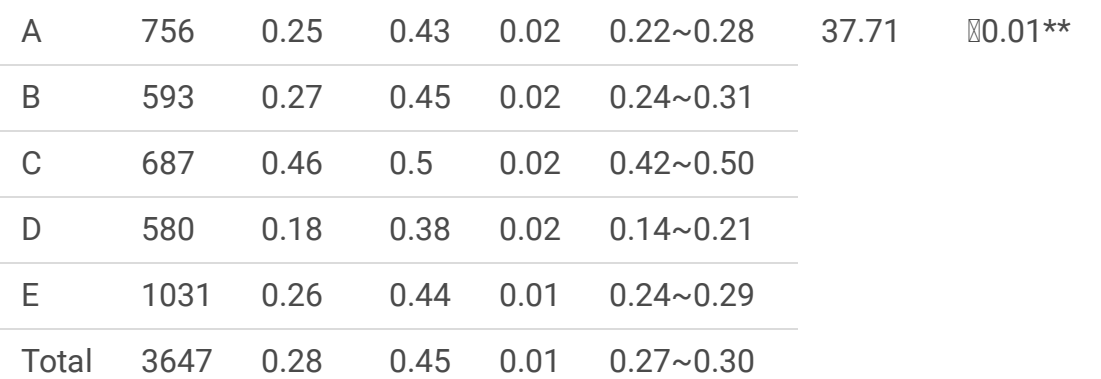

11. Individuals who are taking morphine should also follow a bowel regimen.

\begin{tabular}{|c|c|c|c|c|c|c|c|}
\hline A & 756 & 0.42 & 0.49 & 0.02 & $0.38 \sim 0.45$ & \multirow[t]{6}{*}{17.22} & \multirow[t]{6}{*}{$\nabla 0.01^{\text {** }}$} \\
\hline B & 593 & 0.5 & 0.5 & 0.02 & $0.46 \sim 0.54$ & & \\
\hline C & 687 & 0.63 & 0.48 & 0.02 & $0.59 \sim 0.66$ & & \\
\hline D & 580 & 0.53 & 0.5 & 0.02 & $0.49 \sim 0.57$ & & \\
\hline$E$ & 1031 & 0.55 & 0.5 & 0.02 & $0.52 \sim 0.59$ & & \\
\hline Total & 3647 & 0.53 & 0.5 & 0.01 & $0.51 \sim 0.54$ & & \\
\hline A & 756 & 0.71 & 0.45 & 0.02 & $0.68 \sim 0.75$ & \multirow[t]{6}{*}{37.15} & \multirow[t]{6}{*}{$\otimes 0.01 * \star$} \\
\hline B & 593 & 0.76 & 0.43 & 0.02 & $0.72 \sim 0.79$ & & \\
\hline C & 687 & 0.9 & 0.29 & 0.01 & $0.88 \sim 0.93$ & & \\
\hline D & 580 & 0.91 & 0.29 & 0.01 & $0.88 \sim 0.93$ & & \\
\hline E & 1031 & 0.84 & 0.36 & 0.01 & $0.82 \sim 0.87$ & & \\
\hline Total & 3647 & 0.82 & 0.38 & 0.01 & $0.81 \sim 0.84$ & & \\
\hline$A$ & 756 & 0.66 & 0.47 & 0.02 & $0.63 \sim 0.70$ & \multirow[t]{3}{*}{13.92} & \multirow[t]{3}{*}{$\nabla 0.01^{* \star}$} \\
\hline B & 593 & 0.73 & 0.45 & 0.02 & $0.69 \sim 0.76$ & & \\
\hline C & 687 & 0.78 & 0.42 & 0.02 & $0.75 \sim 0.81$ & & \\
\hline
\end{tabular}

12. To strengthen the construction of hospice care institutions was written into the "healthy China 2030" plan.
13. Morphine point injections can be used for relieve cancer pain in the terminal period. 


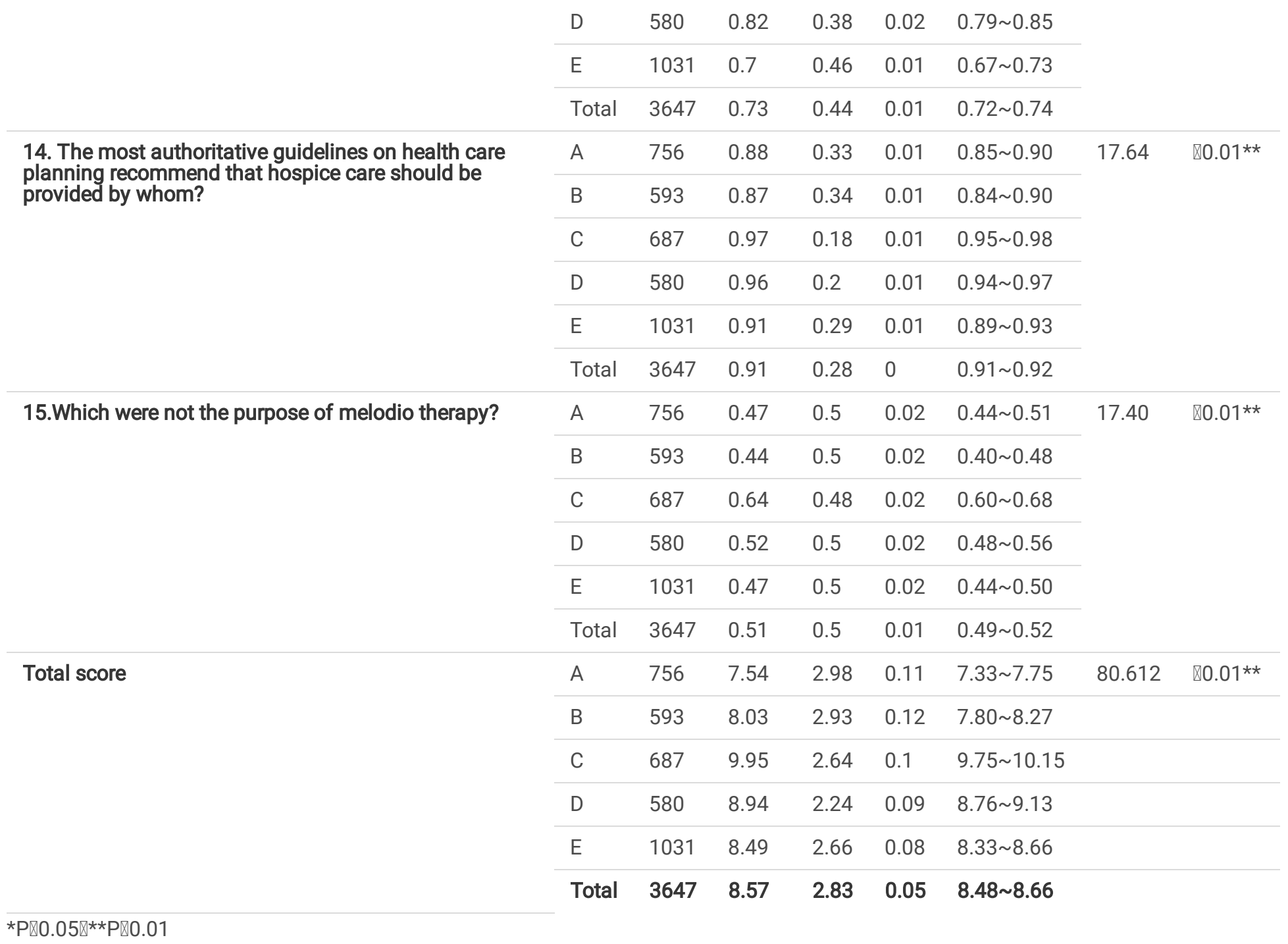

Table 3. The Attitude, Confidence, and Self-report practice Scaling for Respondents from Different Cities 


\begin{tabular}{|c|c|c|c|c|c|c|c|c|}
\hline Scale & City & $\mathbf{N}$ & Mean & SD & S. E & $95 \% \mathrm{Cl}$ & $\mathbf{F}$ & Sig. \\
\hline \multirow[t]{6}{*}{ Attitude } & $A$ & 756 & 88.41 & 11.58 & 0.42 & $87.58 \sim 89.24$ & 64.468 & $P<0.01$ \\
\hline & B & 593 & 88.73 & 11.77 & 0.48 & $87.78 \sim 89.68$ & & \\
\hline & C & 687 & 96.99 & 13.78 & 0.53 & $95.96 \sim 98.02$ & & \\
\hline & $\mathrm{D}$ & 580 & 92.80 & 10.24 & 0.43 & $91.97 \sim 93.64$ & & \\
\hline & $E$ & 1031 & 93.50 & 11.27 & 0.35 & $92.81 \sim 94.19$ & & \\
\hline & Total & 3647 & 92.22 & 12.18 & 0.20 & $91.82 \sim 92.61$ & & \\
\hline \multirow[t]{6}{*}{ Confidence } & $A$ & 756 & 39.37 & 7.99 & 0.29 & $38.80 \sim 39.94$ & 40.98 & $P<0.01$ \\
\hline & B & 593 & 39.62 & 8.65 & 0.36 & $38.92 \sim 40.32$ & & \\
\hline & $\mathrm{C}$ & 687 & 43.60 & 7.84 & 0.30 & $43.01 \sim 44.18$ & & \\
\hline & $\mathrm{D}$ & 580 & 42.79 & 7.16 & 0.30 & $42.21 \sim 43.38$ & & \\
\hline & $E$ & 1031 & 42.23 & 7.59 & 0.24 & $41.77 \sim 42.70$ & & \\
\hline & Total & 3647 & 41.56 & 8.01 & 0.13 & $41.30 \sim 41.82$ & & \\
\hline \multirow[t]{6}{*}{ Self-report practice } & $A$ & 756 & 33.33 & 11.60 & 0.42 & $32.50 \sim 34.16$ & 100.85 & $P<0.01$ \\
\hline & B & 593 & 35.53 & 11.33 & 0.47 & $34.62 \sim 36.45$ & & \\
\hline & C & 687 & 41.93 & 9.80 & 0.37 & $41.20 \sim 42.66$ & & \\
\hline & $\mathrm{D}$ & 580 & 40.43 & 8.93 & 0.37 & $39.70 \sim 41.16$ & & \\
\hline & $E$ & 1031 & 41 & 9.36 & 0.29 & $40.43 \sim 41.57$ & & \\
\hline & Total & 3647 & 38.61 & 10.76 & 0.18 & $38.26 \sim 38.95$ & & \\
\hline
\end{tabular}

Table 4. Multiple Correspondence Analyses of Knowledge, Attitude, Confidence and Self-report practice 


\begin{tabular}{|c|c|c|c|c|c|}
\hline Model & Variables & B & S.E. & $t$ & Sig. \\
\hline \multirow[t]{10}{*}{ Knowledge } & (Constant) & 6.088 & 0.208 & 29.298 & $\nabla 0.001 * *$ \\
\hline & City-C & 1.24 & 0.119 & 10.39 & $\nabla 0.001 * *$ \\
\hline & Willingness on providing hospice care & 1.076 & 0.095 & 11.371 & $\nabla 0.001^{\star *}$ \\
\hline & Education & 0.393 & 0.074 & 5.316 & $\nabla 0.001^{\star *}$ \\
\hline & Experience in providing hospice care & 0.612 & 0.099 & 6.159 & $\nabla 0.001^{\star *}$ \\
\hline & Professional title & 0.199 & 0.057 & 3.476 & $0.001^{\star \star}$ \\
\hline & Rehabilitation nursing & -1.033 & 0.199 & -5.176 & $\nabla 0.001 * *$ \\
\hline & Doctor & 0.384 & 0.097 & 3.95 & $\nabla 0.001 * *$ \\
\hline & $\mathrm{CHC}$ or $\mathrm{THC}$ & -0.302 & 0.095 & -3.183 & $0.001^{\star *}$ \\
\hline & Experience of death witness & 0.246 & 0.104 & 2.37 & $0.018^{*}$ \\
\hline \multirow[t]{9}{*}{ Attitude } & (Constant) & 86.371 & 0.566 & 152.641 & $\nabla 0.001^{* *}$ \\
\hline & Willingness on providing hospice care & 8.636 & 0.384 & 22.502 & $\nabla 0.001 * *$ \\
\hline & City-C & 4.625 & 0.485 & 9.545 & $\nabla 0.001 * *$ \\
\hline & $\mathrm{CHC}$ or $\mathrm{THC}$ & -3.207 & 0.402 & -7.969 & $\nabla 0.001^{* *}$ \\
\hline & Experience in providing hospice care & 2.146 & 0.406 & 5.293 & $\otimes 0.001^{\star *}$ \\
\hline & Experience of death witness & 1.832 & 0.414 & 4.423 & $\nabla 0.001^{\star *}$ \\
\hline & Specialized hospital & 3.080 & 0.816 & 3.772 & $\nabla 0.001$ ** \\
\hline & Rehabilitation nursing & -2.528 & 0.806 & -3.135 & $0.002^{\star \star}$ \\
\hline & Married & -0.867 & 0.423 & -2.051 & $0.040^{*}$ \\
\hline \multirow[t]{7}{*}{ Confidence } & (Constant) & 37.354 & 0.312 & 119.613 & $\nabla 0.001^{\star *}$ \\
\hline & Willingness on providing hospice care & 5.742 & 0.256 & 22.454 & $\nabla 0.001^{\star *}$ \\
\hline & Experience in providing hospice care & 1.443 & 0.271 & 5.325 & $\nabla 0.001$ ** \\
\hline & $\mathrm{CHC}$ or $\mathrm{THC}$ & -1.765 & 0.26 & -6.788 & $\bowtie 0.001$ ** \\
\hline & City-C & 1.678 & 0.324 & 5.183 & $\varangle 0.001^{* *}$ \\
\hline & Experience of death witness & 1.027 & 0.277 & 3.713 & $\nabla 0.001^{\star *}$ \\
\hline & specialized hospital & 1.77 & 0.541 & 3.27 & $0.001 * \star$ \\
\hline \multirow[t]{9}{*}{ Self-report practice } & (Constant) & 30.909 & 0.444 & 69.626 & $\nabla 0.001 * *$ \\
\hline & Experience in providing hospice care & 4.596 & 0.341 & 13.466 & $\varangle 0.001^{\star *}$ \\
\hline & Willingness on providing hospice care & 6.118 & 0.324 & 18.867 & $\nabla 0.001^{\star *}$ \\
\hline & $\mathrm{CHC}$ or THC & -4.434 & 0.317 & -13.98 & $\nabla 0.001^{\star *}$ \\
\hline & Experience of death witness & 2.548 & 0.368 & 6.932 & $\nabla 0.001 * *$ \\
\hline & Doctor & 3.088 & 0.413 & 7.48 & $\nabla 0.001$ ** \\
\hline & City-C & 2.755 & 0.406 & 6.787 & $\varangle 0.001^{\star *}$ \\
\hline & Nurse & 1.869 & 0.415 & 4.505 & $\nabla 0.001^{\star \star}$ \\
\hline & Gender & 1.525 & 0.408 & 3.742 & $\triangle 0.001^{\star *}$ \\
\hline
\end{tabular}

${ }^{\star} \mathrm{P}<0.05,{ }^{* *} \mathrm{P}<0.01$. 
$\mathrm{CHC}$, community health center; THC, township health center.

Table 5. Correlation Analysis of Knowledge, Attitude, Confidence and Self-report Practice

\begin{tabular}{lllll} 
Variables & Knowledge & Attitude & Confidence & Self-report Practice \\
\hline Knowledge & 1 & $0.363^{\star \star}$ & $0.336^{\star \star}$ & $0.331^{\star \star}$ \\
\hline Attitude & $0.363^{\star *}$ & 1 & $0.639^{\star \star}$ & $0.516^{\star \star}$ \\
\hline Confidence & $0.336^{\star \star}$ & $0.639 * \star$ & 1 & $0.631^{\star \star}$ \\
\hline Self-report Practice & $0.331^{\star *}$ & $0.516^{\star *}$ & $0.631^{\star *}$ & 1
\end{tabular}

*P®0.05】**P®0.01

\section{Supplementary Files}

This is a list of supplementary files associated with this preprint. Click to download.

- Appendix1and2.docx 